\title{
Research on Technological Innovation and Economic Growth Mode
}

\author{
Wenzhou Zhang ${ }^{1, *}$ and Chanjun Chang ${ }^{2}$ \\ ${ }^{1}$ Hubei University of Arts and Science, Xiangyang 441053, Hubei, China; ${ }^{2}$ Shiyan Radio \& TV University of Hubei, \\ Shiyan 442000, Hubei, China
}

\begin{abstract}
Economic growth is the result of technological innovation or technology introduction, and it is the promotion of total factor productivity. The role of technological innovation in the transformation of economic growth mode is uncertain. By the factors such as technological gap, digestion and absorption capacity, technological innovation is more complex for the transformation of economic growth mode. In this paper, we find that there is a long-term equilibrium relationship between technological innovation and economic growth in China. There is a serious obstruction in the conduction mechanism between technological innovation and real economy in China. Therefore, the transformation of technological innovation to the real economy should be a long-term important task of our country. Therefore, in the further growth of the economy to continue to technological innovation, it's important to strengthen the digestion and absorption of imported technology, increased technological innovation and personnel training efforts, consolidate and enhance technological innovation capability.
\end{abstract}

Keywords: Cultivation of talents, economic growth, growth pattern, technological innovation.

\section{INTRODUCTION}

With the sustained and rapid economic growth, China's total economic output has leapt to second of the world, and the economic growth achievement is remarkable. But the contradictions that the long-term dependence on the extensive accumulation of investment driven economy grows increasingly, these contradictions become the bottleneck of the sustained and stable economic growth. The economic growth of the economic growth mechanism is the inevitable choice of maintaining the long-term stable growth of the economy. Technological progress (refers only to the narrow sense of technological progress, if not stated, hereinafter referred to technical progress are narrow) is the core driving force of the steady economic growth in the long run, which is to promote the transformation of the mode of economic growth that is the fundamental way that has become a consensus. Technological innovation and technology introduction are two main paths of technological progress but the role of technological innovation and technology introduction to economic growth mode, and there is no consensus conclusion. Research on technology innovation and introduce the results of impact of the economic growth mode transformation many, such as some scholars through the investigation of the effect of independent innovation of total factor productivity to judge technology innovation on economic growth mode transformation effect, some scholars from the effects of technology introduction of total factor productivity or the effects of input and output rate. Judge the introduction technology effect on economic growth mode transformation, but total factor productivity and input-output rate cannot be accurately reflecting the mode of economic growth whether from extensive to intensive change, so these research conclusions is not necessarily reasonable. When the economic growth rate is positive, improving the total factor productivity just set necessary reduced to enhance the level of economic growth rather than sufficient conditions for the input and output rate that can intuitively reflect the economic rate, but the output is the result of the interaction of factor inputs and technological progress, which means that the investment output rate does not accurately reflect the contribution of technological progress to the economic growth. Therefore, the impact of technological innovation and technology introduction on the total factor productivity or the input-output rate can not reflect the impact of technological innovation and technology introduction on the transformation of economic growth mode. This shows that the complexity of the transformation of technological innovation and technology to the economic growth mode needs to be further explored. The technology innovation and technology introduction to economic growth mode transformation to carry out deep that research not only has important theoretical significance, but also to promote the transformation of the mode of economic growth path of technological progress to provide valuable suggestions. The main innovation of this paper is: theory reveal the technology innovation and technology introduction to economic growth way transformation function of uncertainty; investigation of the technology innovation and technology introduction to economic growth way transformation function of difference; by constructing technology innovation and foreign capital participation of multiplicative type using estimation method empirical study of imitative innovation to economic growth in intensive level of judgment to promote transformation of the mode of economic growth path in technological innovation. 


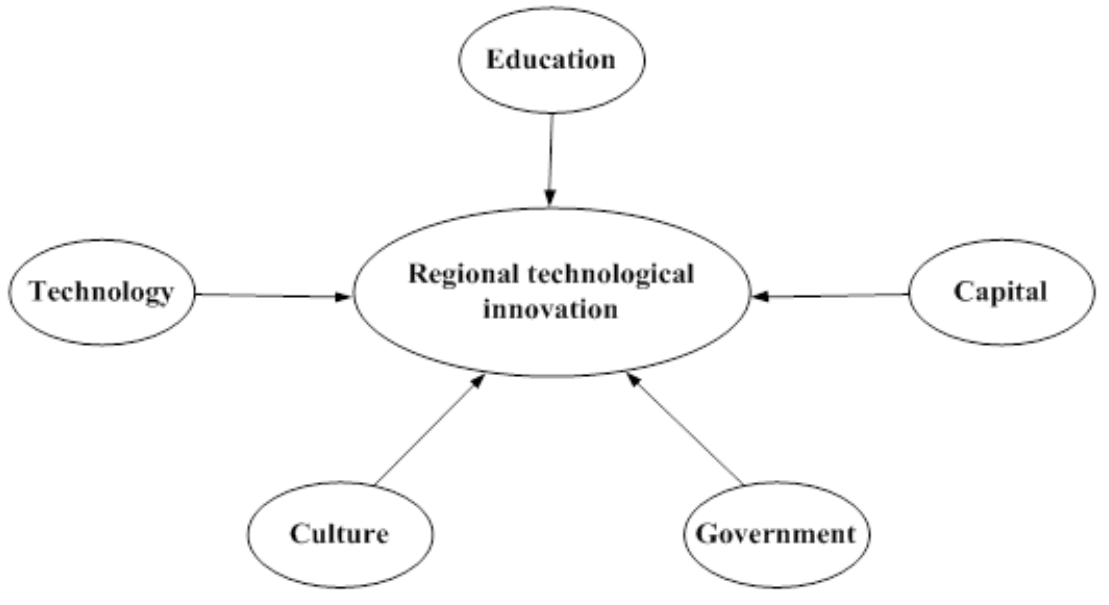

Fig. (1). Regional technological innovation system frame.

\section{TECHNOLOGICAL INNOVATION}

A company, region, country can achieve sustained economic growth, and how, when to achieve sustained economic growth, which is the major issues facing economic development. The answer to the above questions is to build the technological innovation system and promote the development of technology and economy. At present, with the arrival of the era of knowledge economy, "science and technology is the first productive force" has become the consensus of people. Therefore, how to create regional technological innovation system according to the specific questions and tasks according to local conditions has become the key to meet the economic growth.

\section{CONCEPT AND CONSTITUTION OF TECHNO- LOGICAL INNOVATION SYSTEM}

Technological innovation system is the mechanism and system of integrated development of economic, science and technology, education and other factors in a certain social and economic background. Regional technology innovation system is the premise of national technology innovation system and part of that is the bridge of national macro technology innovation and the development of enterprise innovation, its decision goal formulation process is to achieve macro goal of innovation and micro innovation target interactions and mutual fusion process. Regional technological innovation is the concrete of the national macro innovation development decision-making, but also conducive to the development of enterprise innovation. The definition of technological innovation system is shown in Fig. (1).

\section{LATEST PROGRESS OF RESEARCH ON THE DY- NAMIC MODE OF TECHNOLOGICAL INNOVA- TION}

\subsection{The Maximization of the Pure Profit of Innovation}

This model believes that enterprises is the rational "economic man", the pursuit of the goal is to innovate the maximization of pure income. Therefore, whether the enterprise carries on the technological innovation and the innovation power, depends directly on the enterprise to the technological innovation "pure profit" expectation. Specifically, it de- pends on the enterprise's expectations or estimates of innovation earnings, innovation risk, and innovation cost.

\subsection{Multivariate Comprehensive Power Model}

The driving forces for innovation in the pluralism that technology innovation dynamic factors in addition to technology push and demand pull, and some other factors constitute the dynamic source of the technology innovation. According to these factors, we can put the power of innovation theory, and pluralism is divided into theory of three yuan, five yuan and four yuan. Three yuan theory believes that the motivation to promote the technological innovation behavior in addition to technology push and market demand, government organization of technological innovation activities, planning and legal policy, incentive, but also the driving force of technological innovation. The most successful technological innovations are often the result of the combination of technology, market and government. This theory can be expressed in Fig. (2).

Technological innovation power four element theory believes that the technology innovation, in addition to the need to have the technology promotion, market driven and government organization and motivation, also need to innovation subject represents the furniture enterprises have strong innovation desire and higher innovation quality. Motivity of technological innovation of five element theory believes that the dynamic sources of innovation in addition to the above four aspects and factors between self-organization, society, technology and economy of power source of the role of the organization as well as technique innovation.

\subsection{E-E Mode}

The model holds that technological innovation activity is not only influenced by the external environment of innovation, but also closely related to entrepreneur. In the model, science and technology research, trial production, marketing and sales and meet the market demand and technological innovation chain is composed of the four links, and various environmental factors and entrepreneurs factors and the four aspects of interaction, making technology innovation can be achieved. The new idea, new technology and new demand created during the process of this process constitute the foundation of new wheel bed. 


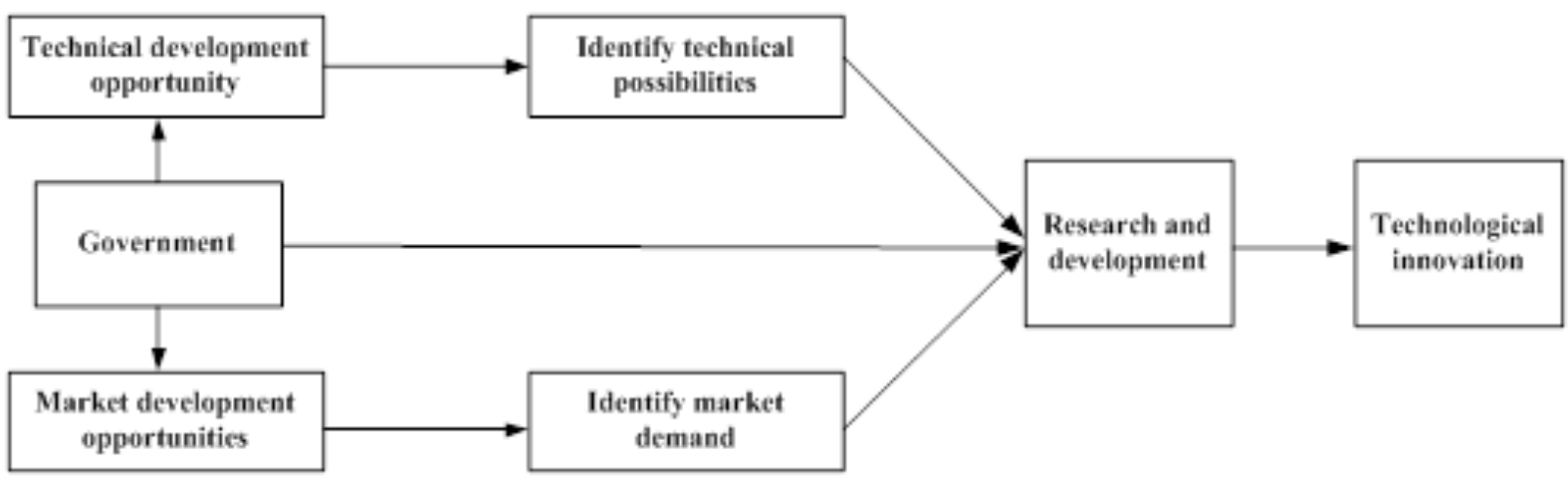

Fig. (2). Theory of three.

\subsection{EPNR Mode}

This is a comprehensive power mechanism, which draws on the rationalization of various power modes, and on this basis, and a new improvement and synthesis. The elements of EPNR comprehensive model include: enterprise, policy, demand and resources. The model described the dynamic mechanism is: under the pressure of the external environment and the pursuit of the maximum benefit of the internal driving force of the dual role, when the enterprise in the identification and evaluation of environmental consciousness to the contradiction between resource and demand or not timely, it will produce innovative technology requirement.

\subsection{Expectation Theory Model}

The theoretical model is expected from psychologists Vroom. V.H from technical innovation model constructed by the expectation theory. Enterprise technology innovation is high input, high risk and income lag characteristics; enterprises in the face of lagging and uncertainty of market returns to and the future trend of the innovation decision of economic, scientific, technological and other variables are analyzed and forecasted and make a rational choice, according to the theory. Only while the probability of innovation and higher expectations of innovation, the enterprise will be technological innovation.

\section{MAIN CONTENTS OF NATIONAL INNOVATION SYSTEM RESEARCH}

First, the main content of technological innovation is the flow of knowledge and knowledge. The main raw material of technological innovation is knowledge, and can be divided into two kinds of knowledge and knowledge required by customers. The second is organization and system of technological innovation. The carrier of technological innovation is organization, including enterprise, University, research institution and government agency, etc. The rule of organization activity is system, and the system of technological innovation is a subset of the system. Third, the essence of the national innovation system is to promote the system of technological innovation. The behavior of the enterprise is made by the system, which includes the restriction and stimulation of the innovation, such as law, rule, culture standard, social criterion and technical standard. The technological innova- tion activity is embedded in the system environment, has the obvious country, the region characteristic.

\section{THEORETICAL MODEL OF THE RELATIONSHIP BETWEEN TECHNOLOGICAL INNOVATION AND ECONOMIC GROWTH}

The market demand and the technical level are the starting point and the essential power of technological innovation activity. A number of new technologies to a new product as the carrier of technical feasibility and market selection results of interaction and formed a dominant design, when the dominant design is gradually being accepted by the market and technology tend to be mature and large-scale production and become technical standards. The level and speed of technological innovation and the level of technological innovation are determined by the technology standard and the speed of renewal. The technology standard becomes the platform of technological innovation, which decides the direction of technological innovation, and promotes or hinders the development of technological innovation activities in a certain extent.

The formation of technological standards for the industrial enterprise technological innovation activities set a clear target and behavior reference system, and promote the diffusion and collaboration of industrial technology, provide the interface for industry collaboration. Industrial vertical and horizontal correlation, and the coordination of high-tech industry and traditional industries, promote the optimization of industrial structure and the formation of emerging industries, and thus promote economic growth. Technological innovation through improving the marginal productivity of social labor productivity and factor of production, change the quality of the products and the difference, driven to optimize the industrial structure and the formation of new industries, directly or indirectly to promote economic growth. Economic growth has evoked a new market demand, and may promote the improvement of the technology level, and thus launches a new round of the circular function process. Obviously, mutual promotion and mutual restriction relationship exist among technical standards, technical innovation and economic growth, technical standards and technological innovation to economic growth has a positive role in promoting economic growth and provide material foundation for improving a new round of technological innovation and the level of technical standards. The theoretical model of the 


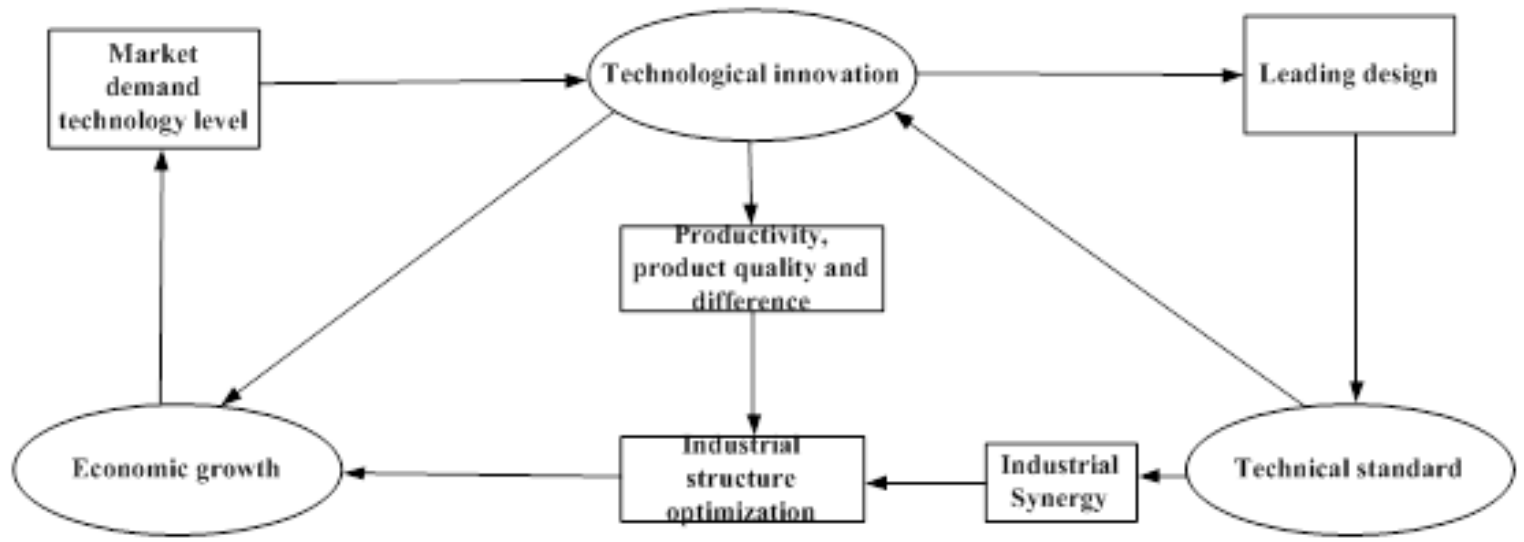

Fig. (3). Theoretical model of the relationship between technological standard, technological innovation and economic growth.

Table 1. Variable Adf test results.

\begin{tabular}{|c|c|c|c|c|c|}
\hline Variable & The Number of ADF & $\mathbf{1 \%}$ Critical Values & $\mathbf{5 \%}$ Critical Values & $\mathbf{1 0 \%}$ Critical Values & Conclusion \\
\hline \hline LGDP & -2.51938 & -4.667883 & -3.7332 & -3.310349 & Not stable \\
\hline LGJC & 0.42195 & -4.728363 & -3.759743 & -3.324976 & Not stable \\
\hline KXJ & -2.76272 & -4.532598 & -3.673616 & -3.252546 & Not stable \\
\hline ZL & -0.70222 & -4.532598 & -3.673616 & -3.774641 & Not stable \\
\hline DLGDP & -4.94234 & -4.80008 & -3.791172 & -3.345677 & Stable \\
\hline DLGJC & -4.27482 & -4.728363 & -3.759743 & -3.168445 & Stable \\
\hline DKXJ & -4.11268 & -4.616209 & -3.710482 & -3.456547 & Stable \\
\hline DZL & -4.68751 & -4.571559 & -3.465674 & Stable \\
\hline
\end{tabular}

relationship between technological standards, technological innovation and economic growth is shown in Fig. (3).

\section{COINTEGRATION INTEGRATION OF TECHNO- LOGICAL INNOVATION AND ECONOMIC GROWTH}

This paper uses 1985 2004 to carry out empirical test of relevant data of our country, and sample data are collected from 5 statistical yearbook of China in each year. Empirical research variable selection of gross domestic product (GDP) said economic growth indicators. Because of the characteristics of technological innovation, we can't directly measure the quality and quantity of technological innovation. We only choose some indexes to express the technological innovation indirectly. This paper mainly from the input and output of technological innovation chooses the national finance for scientific research (GJC), scientists and engineers (kxj), patent application authorization number (ZL) of these three fingers. Indicators of technological innovation of the subject. Due to the natural logarithm transform of data, it does not change the original cointegration relationship, and the trend of linearization, eliminate time series in the presence of heteroskedasticity phenomenon, and because the logarithm of the number of scientists and engineers and to apply for a patent authorization are I (0), so it's not the two index logarithmic, and GDP and the state financial for scientific re- search expenditure index is higher order integration that were obtained from the natural logarithm, which is denoted as LGDP, LGJC.

\subsection{Stationary Test of Variable}

In 1986, Phillip proved that if the two time series were subject to a unit root process, then even between them did not exist any correlation, when the sample size increases, to a time series of the other a time series regression would always get significant parameters, which is the so-called / pseudo return 0 . The fundamental cause of the false regression is the non - stationary of the sequence. Therefore, in the regression analysis of time series data, the stability of the time series variables should be examined firstly. Inspection methods used ADF test. In the test, according to the basic sequence diagram, it is determined whether the cross section and the time trend are there or not, and that is the basic form of ADF test. The concrete way of our inspection unit root is:

Assuming the data generation process is:

$$
\text { yt }=\text { A+ Qyt-1+N1vyt-1+N2vyt-2+,+ Np-1vyt-p+Et }
$$

Among them, $\{\mathrm{Et}\}$ is independent and identically distributed, $\mathrm{E}(\mathrm{Et})=0$, $\operatorname{Var}(\mathrm{Et})=\mathrm{R} 2<1$

Now, inspect

$\mathrm{H} 0: \mathrm{Q}=1 ; \mathrm{Q}<1$ 
Table 2. Cointegration test results of johsansen.

\begin{tabular}{|c|c|c|c|c|}
\hline $\begin{array}{c}\text { Number of Hypotheses for } \\
\text { Cointegration }\end{array}$ & Maximum Feature & Trace Statistics & 0.05 Critical Value & The Value of P \\
\hline \hline None & 0.831276 & 58.43560 & 47.86481 & 0.0034 \\
\hline At most 1 & 0.567345 & 26.06455 & 29.84325 & 0.107 \\
\hline At most 2 & 0.425677 & 10.43556 & 15.56774 & 0.2168 \\
\hline At most 3 & 0.04684 & 0.856544 & 3.54674 & 0.3557 \\
\hline
\end{tabular}

Table 3. Standard cointegration vector coefficient.

\begin{tabular}{|c|c|c|c|}
\hline LGDP & LGJC & KXJ & ZL \\
\hline \hline 1.00000 & -0.383544 & -0.000672 & $-1.87 \mathrm{E}-0.6$ \\
\hline & -0.27025 & -0.00301 & $-4.60 \mathrm{E}-06$ \\
\hline
\end{tabular}

Table 4. The result of granger causality detection between the variables.

\begin{tabular}{|c|c|c|c|}
\hline Original Hypothesis & Lag Order & F Statistics & P Statistics \\
\hline \hline LGJC is not the cause of Granger LGDP & \multirow{2}{*}{2} & 5.85633 & 0.01537 \\
\cline { 1 - 3 } LGDP is not the cause of Granger LGJC & \multirow{2}{*}{6} & 9.74325 & 0.0026 \\
\cline { 1 - 3 } KXJ is not the cause of Granger LGDP & \multirow{2}{*}{1} & 43.346 & 0.11575 \\
\cline { 1 - 3 } LGDP is not the cause of Granger KXJ & & 830.7223 & 0.02655 \\
\cline { 1 - 3 } ZL is not the cause of Granger LGDP & & 2.87763 & 0.10918 \\
\cline { 1 - 3 } LGDP is not the cause of Granger ZL & & 4.31114 & 0.05434 \\
\hline
\end{tabular}

According to the Red pool information criterion (AIC), the lag order number is determined, and finally, whether the ADF statistic is stable or not. Test results are shown in Table 1.

Table 1 shows that we can't reject the assumption of unit root for the 1 time series of LGDP, LGJC, KXJ and ZL. The first order difference of the four variables can be rejected under the significant level of 0.05 . It can be considered that the four variables are subject to I (1) process.

\subsection{Inspection and Estimation of Cointegration Relation- ship Among Variables}

Some time series, although they are not stable, but some linear combination is stable. This linear combination reflects the long-term and stable proportional relationship among the variables, and it is called the cointegration relationship. Therefore, there is a long-term and stable equilibrium relationship between the variables and the cointegration. In this relationship any short-term deviation of the variable will eventually return to the long-term equilibrium path, and there should be a kind of mutual information feedback between the variables. Granger Engle proposed two step method in 1987 to test the cointegration relationship between the two variables, and the test of the cointegration relationship among the variables is inconvenient. Johansen and
Juse2lius proposed a new method of auto regression (Johansen test), which can be used to test multiple variables, and some kinds of co integration relations among them are also presented. The cointegration test requires that the time series are the same order, and the four variables in this paper are the 1 order and cointegration, and meet the requirements of cointegration analysis. The results of the whole test are shown in Table 2.

Through Table 2 , at the level of $5 \%$, there is only a cointegration relationship with the assumption, so that there is no cointegration relationship.

VECM will be the co integration of the relationship between the written. Vecm = LGDP- 0.38LGJC$0.000672 \mathrm{KXJ}-1.87 \mathrm{E}-06 \mathrm{ZL}$.

The unit root test of sequence VECM is carried out, which is found that it is a stationary sequence, and the relationship is correct, and the relationship between the four time series is reflected by the formula.

\subsection{Grainger Causality Test}

Granger proposed the causality test that can solve this kind of problem. In this paper, based on VAR model Granger test of whether there is a causal relationship between the technological innovation and economic growth 
test, due to the model test results sensitivity dependence on the choice of lag. Therefore, for the inspection according to the following rule selection lag: first according to the criterion of AIC and SC, cannot be determined, according to the Neyman) Pearson proposed likelihood ratio test [14]. The results of the test are shown in Table 4.

From the above test results, we know: under 0.05 level of significance, the gross domestic product (GDP) and the national finance for scientific research expenditure become both cause and effect relationship, and scientists and engineers and the number of patent application authorization number and gross domestic production is a one-way causal relationship. That is, the total GDP is the number of scientists and engineers and the number of patent applications for Granger reasons. The Granger causality test can be said economic growth that is the Granger cause of technological innovation, and technology innovation is not economic growth's Granger causes, between them in one-way causality.

\subsection{Results and Theoretical Interpretation}

From the above analysis results, we get the basic conclusion that: there is a long-term equilibrium relationship between technological innovation and economic growth in China, but there is no two-way relationship between the two, and there is only a one-way relationship, that is, the technological innovation has no significant effect on the Granger, while the actual economic growth has the impact on the technological innovation ability, which is obviously contradictory to the results of previous studies. Because both the new classical growth theory and endogenous growth theory that technology in economic growth has a decisive role, the corresponding test results are to be technological innovation on the actual economic growth rate has a positive Granger effect. For the above, we believe that the statistical test results can not deny that the endogenous growth theory conclusion, but in greater extent that our technology innovation and economic existence transmission mechanism on the block. So the results of technology innovation in our country only effectively translated into practical productive forces, which can be manifested in the real economic growth contribution. This is the root because of the results of statistical testing. At the same time, the results of the above analysis show that there is a certain degree of decoupling between the scientific research project and the real economy in China. The coefficients in the cointegration slightly negative to show that technological innovation on China's economic growth did not produce an obvious role in promoting, due to the national finance for scientific research, expenditure is the Granger cause of economic growth. Therefore, in order to to achieve sustained economic growth required more knowledge, technology and human capital must through self investment consciousness raise.

\section{CONCLUSION}

Theoretical analysis shows that due to the opportunity cost, the introduction of technology of path dependence and the research and development of the reverse spillover and other reasons, under certain conditions, technological innovation on the economic growth mode transformation of the role is uncertain. By the technological gap, factor endowment, absorptive capacity, the role of technological innovation in the transformation of economic growth mode is uncertain. To use China's Regional Panel Data and use the estimation method for the inspection found that technology innovation and economic growth intensive level are significantly negative correlation, the FDI Technology Spillover on economic growth intensive level has significant positive effects. Further construct containing the technology innovation and foreign capital participation degree of the multiplication of model test showed that imitative innovation to economic growth intensive level has significant positive effects. The conclusion of this research has clear policy implications for the choice of technological progress path for accelerating economic growth mode transformation in China. In the next long period, we must continue to insist on the introduction of foreign investment technology strategy. Because foreign technology spillover is an important factor to promote the economic growth mode from extensive to intensive. Under the new situation, foreign investment technology should focus on improving the foreign technology, encouraging investment in European and American developed countries, encouraging foreign investment to encourage foreign investment in high-tech industries and developing foreign investment. To encourage the local procurement of foreign investment into a higher proportion of foreign expansion effect of backward linkages. At the same time, the provisions of foreign enterprises create added value proportion of and raising tariffs on intermediate inputs imported by foreignfunded enterprises, to improve the degree of localization of foreign-funded enterprises that employed in foreign-funded enterprises of local technical personnel to accept more production processes in the technology, expand FDI technology spillover effect. Secondly, the government should increase the introduction of digestion and absorption of technology efforts emphasizing imitation and innovation, in a relatively short period of time low cost increase speed of the accumulation of knowledge and technology innovation narrow the technology gap with the developed countries, for independent innovation lay a solid foundation. In the introduction digestion and absorption - imitation innovation based, we should pay attention to the independent innovation ability of the formation to enhance the level of independent innovation, change backward, the introduction and then backward and the introduction of low level circulation eliminate technology introduction of path dependence, lift manufacturing technology industry low-end locking, break the control on technology and high-end profits in developed countries, improve enterprise in the international market the competitiveness of core technology, which achieve sustained and stable economic growth.

\section{CONFLICT OF INTEREST}

The authors confirm that this article content has no conflict of interest.

\section{ACKNOWLEDGEMENTS}

Declared none. 


\section{REFERENCES}

[1] F. Jiaji, L. Jiaxiao, and C. Yuan, "Frontier Technology Economics," Beijing: Economic Science Press, 2003.

[2] F. Xiang, and J. Luorong, "Between scientific research investment and economic growth in China and the associated analysis," Tax and Economy, vol. 03, pp. 1-6, 2005.

[3] S. Jianchu, F. Fangzhi, and Z. Gengqing, "Technological innovation, economic growth and government intervention," Statistics and decision-making, vol. 1, pp. 1-6, 2005.

[4] W. Shenghan, "Technological innovation and economic growth," Journal of Longyan Teachers College, vol. 5, pp. 1-10, 2001.

[5] C. Ying, "Technological innovation and economic growth," Nankai Economic Research, vol. 5, pp. 44-50, 2004.

[6] X. Zhuqing, "Patents, technological innovation and economic growth: theory and empirical," Research Management, vol. 5, pp. 2004

[7] D. Romer, "Advanced Macroeconomics," Commercial press, 1999.

[8] L. Fengliang, and G. Jie, "Resource can exhaustion, knowledge accumulation and endogenous economic growth," Journal of Central University of Finance and Economics, vol. 11, pp. 2002.
[9] Z. Ziying, "The technology progress and the long-term economic growth of China's economy," Journal of Wuhan University, vol. 05, pp. 23-35, 1998

[10] Wang Hao, Zhang Mougui The contribution of technological progress to economic growth and the definition of economic growth mode, Statistical education, 2005, (08).

[11] Morales, M.F. Research policy and endogenous growth, Spanish Economic Review, 2004,(6):179 - 209.

[12] Kai, Jakobs, Information Technology Standards and Standardization: A Global Perspective, USA: Idea Group Publishing,2000.

[13] Murat, Iyigun. Clusters of invention, life cycle of technologies and endogenous growth. Journal of Economic Dynies \& Conrtol, 2006 , (30):687-719.

[14] Li Shiyong, Tian Xinhua. Nonlinear science and complexity science, .Harbin: Harbin Institute of Technology press, 2006,152.

[15] Hu Caimei, Wei Fulei, Empirical research on the relationship between technological innovation, technological standardization and economic growth of China, Technology and economy, 2011, 24 (3):16-20.

Received: June 10, 2015

Revised: July 29, 2015

Accepted: August 15, 2015

(C) Zhang and Chang; Licensee Bentham Open.

This is an open access article licensed under the terms of the (https://creativecommons.org/licenses/by/4.0/legalcode), which permits unrestricted, noncommercial use, distribution and reproduction in any medium, provided the work is properly cited. 